\section{Commentary: Invasive, but indispensable: Hemodynamic assessment to comprehend interventricular interactions}

\author{
Justin T. Tretter, MD, and Andrew N. Redington, MD
}

It was almost a century ago, in 1929, that Dr Werner Forssmann, intrigued by the recording of intracardiac pressures in horses reported 70 years previously, would pass a ureteral catheter through his own antecubital vein and obtain an $\mathrm{X}$-ray showing it in his right atrium. ${ }^{1}$ A decade or so later, stimulated by Forssmann's groundbreaking work, pulmonologists Drs André Cournand and Dickinson Richards formed a famous collaboration to quickly establish invasive hemodynamic assessment of their patients as the basis of modern cardiology. ${ }^{2}$ The 3 physicians would later share the Nobel Prize in Medicine in 1956.

There followed an explosion of basic and clinical research establishing invasive hemodynamic and functional assessment as the gold standard to describe right and left ventricular function individually, as well as forming the basis for our understanding of the complex interplay between the right and left ventricles as a functional unit. This is true both in the normal heart and those with various abnormal pressure and volume loads. 3,4

In 1956, Dr Abraham Rudolph would become the first congenital cardiologist to perform a cardiac catheterization in a young infant, subsequently helping to establish it, then, as the primary tool for diagnosis and, more recently, treatment of congenital heart disease. ${ }^{5}$ Straddling the era of invasive hemodynamic research and the understandable concentration on noninvasive diagnosis

\footnotetext{
From the Department of Pediatrics, Cincinnati Children's Hospital Medical Center, Heart Institute, University of Cincinnati College of Medicine, Cincinnati, Ohio. Disclosures: The authors reported no conflicts of interest.

The Journal policy requires editors and reviewers to disclose conflicts of interest and to decline handling or reviewing manuscripts for which they may have a conflict of interest. The editors and reviewers of this article have no conflicts of interest.

Received for publication Aug 16, 2021; revisions received Aug 16, 2021; accepted for publication Aug 17, 2021; available ahead of print Aug 21, 2021

Address for reprints: Justin T. Tretter, MD, Cincinnati Children's Hospital Medical Center, Heart Institute, 3333 Burnet Ave, Cincinnati, OH 45229 (E-mail: justin. tretter@cchmc.org).

J Thorac Cardiovasc Surg 2022;163:e309-10

$0022-5223 / \$ 36.00$

Copyright (c) 2021 by The American Association for Thoracic Surgery https://doi.org/10.1016/j.jtcvs.2021.08.046
}

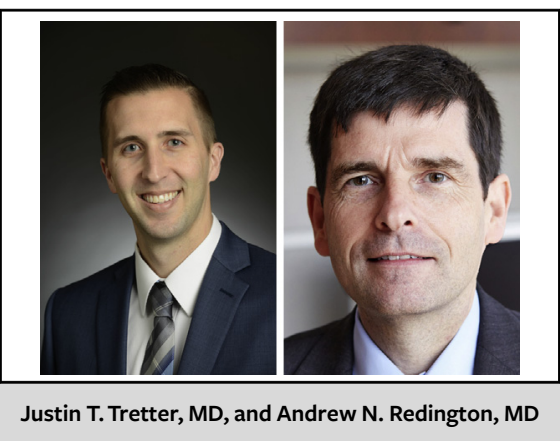

\author{
CENTRAL MESSAGE \\ This article demonstrates the \\ occurrence of adverse interven- \\ tricular interactions in both the \\ volume- and pressure-loaded \\ right ventricle.
}

and functional assessment, the use of invasive assessment of complex hemodynamics as a foundational gold standard in congenital diseases was, perhaps, abandoned too soon. We ourselves have jumped on the bandwagon in exploring and promoting noninvasive means toward understanding hemodynamics and functional parameters, which, until recently, could only accurately be assessed invasively. 6,7

We commend Jani and colleagues ${ }^{8}$ for bringing us back to our foundational roots in this excellent, albeit small, cohort animal study on the effects of pressure and volume loading of the right ventricle on interventricular interactions. Many of the adverse findings reported in this study are consistent with noninvasive investigations in patients with repaired tetralogy of Fallot, both those with pressureor volume-loaded right ventricles. For example, it has been demonstrated in this population with a volume-loaded right ventricle that diastolic interventricular septal flattening correlates with increased pulmonary regurgitation, right ventricular volumes, and QRS duration, as well as decreased right and left ventricular ejection fractions.' Diastolic interventricular septal flattening in combination with the common occurrence of right ventricular restrictive physiology in this population has also been correlated to impaired left ventricular filling as assessed by echocardiography. ${ }^{10}$ The current study demonstrated prolonged left ventricular filling time due to elevated left ventricular end-diastolic pressure and an increase in isovolumic relaxation time in animals with a volume-loaded right ventricle. ${ }^{8}$ It is only by the additional insight provided in 
these types of invasive studies that will help to complement and fill in the gaps in knowledge regarding this complex ventricular-ventricular interplay, which involves a combination of mechanical, electromechanical, and neurohormonal coupling. ${ }^{4}$

Have we missed the opportunity to perform such studies in our patients? We think not. A thorough understanding of the consequences of our actions after the surgical and nonsurgical treatment of congenital heart diseases will continue to unfold over decades. We clearly are still learning about those consequences, primarily using noninvasive assessments, and largely in the absence of foundational invasive observations. We would argue that intermittent cardiac catheterization studies, particularly using the sophisticated pressure-volume catheters described by Jani and colleagues ${ }^{8}$ and by us in patients previously, ${ }^{11}$ cannot only be justified on a risk-benefit basis, but that we owe it to our patients that they form a component of the fundamental assessment of the unique hemodynamic consequences of their congenital heart diseases and its treatment.

In summary, while we would not be so bold as $\mathrm{Dr}$ Forssmann, reportedly walking himself up one flight of stairs to the X-ray department to document his self-catheterization, we would, however, be bold enough to risk accusations of being "dinosaurs" in appealing to our field to selectively restore invasive hemodynamics as a gold-standard research and clinical tool to complement and better understand our noninvasive assessments.

\section{References}

1. Forssmann W. Die Sondierung des rechten Herzens [probing of the right heart] Klin Wochenschr. 1929;8:2085-7 [in German].

2. Cournand A, Lauson AHD, Bloomfield RA, Breed ES, Baldwin EF. Recording of right heart pressures in man. Proc Soc Exp Biol Med. 1945;60:73-5.

3. Brookes C, Ravn H, White P, Moeldrup U, Oldershaw P, Redington A. Acute right ventricular dilatation in response to ischemia significantly impairs left ventricular systolic performance. Circulation. 1999;100:761-7.

4. Tretter JT, Redington AN. The forgotten ventricle? The left ventricle in rightsided congenital heart disease. Circ Cardiovasc Imaging. 2018;11:e07410.

5. Hoffman JI. Abraham Morris Rudolph: an appreciation. Pediatrics. 2002;110: 622-6.

6. Friedberg MK, Redington AN. Right versus left ventricular failure: differences, similarities, and interactions. Circulation. 2014;129:1033-44.

7. Tretter JT, Pradhan S, Truong VT, Mullikin A, Mazur W, Hill GD, et al. Noninvasive left ventricular myocardial work indices in healthy adolescents at rest. Int J Cardiovasc Imaging. 2021;37:2429-38.

8. Jani V, Konecny F, Shelby A, Kulkarni A, Hammel J, Schuster A, et al; Right Heart Research Group (Danford D, Kutty S). Influence of right ventricular pressure and volume overload on right and left ventricular diastolic function. $J$ Thorac Cardiovasc Surg. 2022;163:e299-308.

9. Muzzarelli S, Ordovas KG, Cannavale G, Meadows AK, Higgins CB. Tetralogy of Fallot: impact of the excursion of the interventricular septum on left ventricular systolic function and fibrosis after surgical repair. Radiology. 2011;259: 375-83.

10. Ahmad N, Kantor PF, Grosse-Wortmann L, Seller N, Jaeggi ET, Friedberg MK, et al. Influence of RV restrictive physiology on LV diastolic function in children after tetralogy of Fallot repair. J Am Soc Echocardiogr. 2012;25:866-73.

11. Derrick GP, Narang I, White PA, Kelleher A, Bush A, Penny DJ, et al. Failure of stroke volume augmentation during exercise and dobutamine stress is unrelated to load-independent indexes of right ventricular performance after the Mustard operation. Circulation. 2000;102:III154-9. 